\title{
RAPD Profiling of Three Japanese Drosera Species
}

\author{
Santhita Tungkajiwangkoon ${ }^{1}$, Ayato Inagaki ${ }^{2}$, Junichi Shirakawa ${ }^{3}$ and Yoshikazu Hoshi ${ }^{4 *}$ \\ ${ }^{1}$ Graduate School of Bioscience, Tokai University, Kawayo, Minamiaso-mura, Aso-gun, \\ Kumamoto 869-1404, Japan \\ ${ }^{2}$ Plant Physiology and Fruit Chemistry Division, National Institute of Fruit Tree Science, \\ National Agriculture and Food Research Organization, Tsukuba, Ibaraki 305-8605, Japan \\ ${ }^{3}$ Department of Bioscience, School of Agriculture, Tokai University, \\ Kawayo, Minamiaso-mura, Aso-gun, Kumamoto 869-1404, Japan \\ ${ }^{4}$ Department of Plant Science, School of Agriculture, Tokai University, \\ Kawayo, Minamiaso-mura, Aso-gun, Kumamoto 869-1404, Japan
}

Received February 22, 2015; accepted March 9, 2015

\begin{abstract}
Summary RAPD analysis was carried out using 1200 decamer random sequences to clarify the whole fingerprint of DNA fragment appearance patterns among three Japanese Drosera species: $D$. tokaiensis, D. rotundifolia and D. spatulata. The RAPD analysis results showed that $D$. tokaiensis had not only magnificent bands common to other two species, but also many specific bands, although D. tokaiensis is of amphiploidal origin between D. rotundifolia and D. spatulata. The specific bands of $D$. tokaiensis might generate after the speciation or amphiduplication. Therefore, the relationship of genome compositions among the three species suggested that RAPD fragments were preferentially amplified from 20 middle-sized chromosomes in D. rotundifolia and D. tokaiensis. Thus, the chromosome information and the RAPD profiling suggested that alloploidal genome formation during Drosera speciation might obtain new beneficial genetic characters to survive and adapt to certain environments.
\end{abstract}

Key words Cytogenetics, Drosera rotundifolia, Drosera spatulata, Drosera tokaiensis, Genome, RAPD.

Carnivorous plants are a group with highly specialized morphology for insect trapping, and thus appeal to botanists (Juniper et al. 1989, Rivadavia et al. 2003, Bhau et al. 2009, Hoshi et al. 2010). The Droseraceae, which is a representative family of carnivorous plants, contains three genera of Aldrovanda, Dionaea and Drosera (Takahashi and Sohma 1982, Juniper et al. 1989, Conran et al. 1997, Williams et al. 1994, Rivadavia et al. 2003). In contrast to the two monotypic genera Aldrovanda and Dionaea, Drosera is one of the largest genus, consisting of approximately 150 species and distributed worldwide (Rivadavia et al. 2003). Many Drosera species, especially the Northern Hemisphere species, show the basic chromosome number of $x=10$ with differences in ploidy level and chromosome size (Hoshi et al. 2010), and most of the species belong to section Drosera of subgenus Drosera (Seine and Barthlott 1994).

Three related species in this section with $x=10$ are found in Japan. Drosera rotundifolia L. spreads widely in the Northern Hemisphere (Rivadavia et al. 2003). In Japan, this species occurs in the main Islands except the Ryukyu Islands (Horikawa 1976, Nakano et al. 2004). The leaves of the species are spoon-shaped (Nakano et al. 2004, Shirakawa et al. 2012, Hoyo and Tsuyuzaki 2013), and all plants are the diploid with middle size $(2-3 \mu \mathrm{m})$ of metaphase chromosomes $(2 n=2 x=20 \mathrm{M})$ (Fig. 1A). Drosera spatulata Labill. is often treated as a complex, first

\footnotetext{
*Corresponding author, e-mail: yhoshi@agri.u-tokai.ac.jp

DOI: $10.1508 /$ cytologia. 80.393
} 

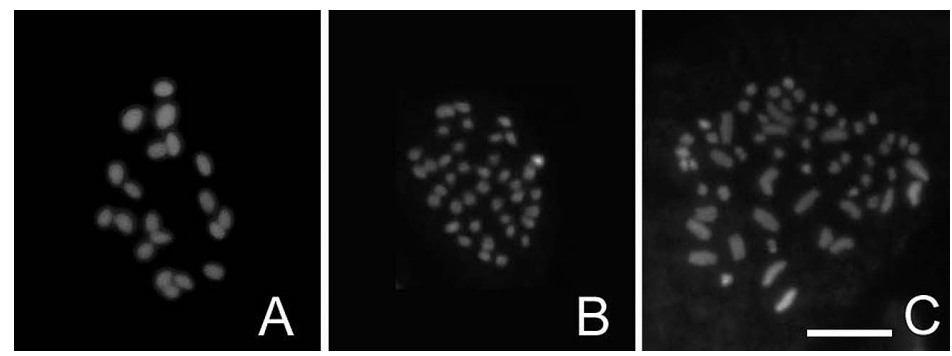

Fig. 1. Fluorescence staining of mitotic-metaphase chromosomes with DAPI. A. D. rotundifolia $(2 n=2 x=20 \mathrm{M})$. B. D. spatulata $(2 n=4 x=40 \mathrm{~S})$. C. D. tokaiensis $(2 n=6 x=20 \mathrm{M}+40 \mathrm{~S})$. Bar $=5 \mu \mathrm{m}$.

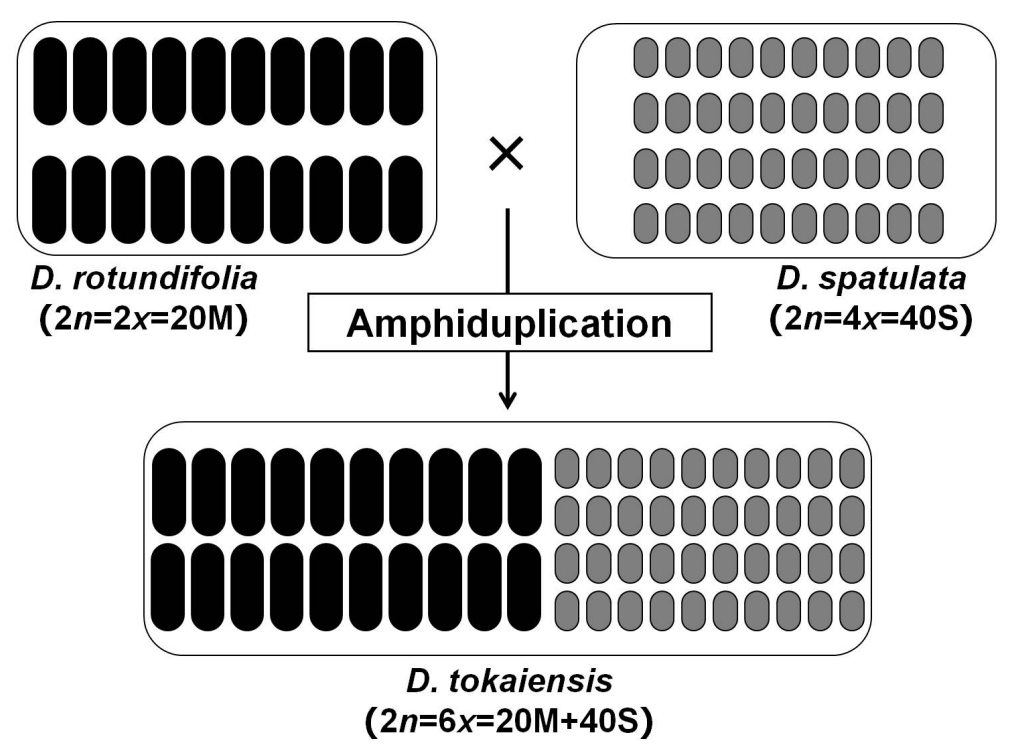

Fig. 2. Schematic illustration of chromosomal relationship among three Japanese species, D. rotundifolia, D. spatulata and D. tokaiensis.

reported in Tasmania, mainly distributed in Australia, New Zealand, some parts of southeast Asia, Taiwan, southern China and Japan (Merrill 1923, van Steenis 1953, Allan 1961, Marchant and George 1982, Nakano et al. 2004). Natural habitats of D. spatulata in Japan are located in the southern areas: Ryukyu, Kyushu and Shikoku Islands, and the west coastal regions of Honshu (Nakano et al. 2004). The leaves of the species are spatulate in shape (Nakano et al. 2004, Hoshi et al. 2008, Hoshi et al. 2010). The plants native to Japan are tetraploid and have small size (approximately $1 \mu \mathrm{m})$ of metaphase chromosome $(2 n=4 x=40 \mathrm{~S})$ (Fig. 1B). Drosera tokaiensis (Komiya and Shibata) Nakamura and Ueda is a recently recorded hexaploid-species with hybrid origin $(2 n=6 x=20 \mathrm{M}+40 \mathrm{~S})$ (Fig. 1C). The parental ancestors of D. tokaiensis are D. rotundifolia as the paternal origin and D. spatulata as the maternal origin (Shirakawa et al. 2012) (Fig. 2). Drosera tokaiensis is found only in Japan, particularly in the Kansai district, Shikoku, the Pacific side of the central parts of Honshu, Tokai district and spread out inland (Nakano et al. 2004). The leaves of this species show an intermediate leaf shape between obovate and spatulate (Nakano et al. 2004, Hoshi et al. 2008, Hoshi et al. 2010).

In contrast to many previous phylogenetic works of RAPD (Sharma et al. 1995), our recent preliminary investigation showed various RAPD DNA band patterns with no phylogenetic relation to the Japanese Drosera species (Hoshi et al. 2010). Interestingly, even though D. rotundifolia and D. spatulata are both parental species of $D$. tokaiensis, the main RAPD bands preferentially occur 
on D. rotundifolia and D. tokaiensis, but not D. spatulata (Hoshi et al. 2010).

The purpose of this research is to clarify the overall picture of appearance patterns of RAPD DNA fragments among the three Japanese Drosera species in molecular profiling using whole 1200 RAPD primers.

Materials and methods

\section{Plant materials}

The plant materials were collected from three Drosera species: D. rotundifolia L., D. spatulata Labill. and D. tokaiensis (Komiya and C. Shibata) T. Nakamura and Ueda (Table 1). Leaf materials of the plants were obtained from tissue culture in the Laboratory of Plant Environment Science, Department of Plant Science, School of Agriculture, Tokai University. The plants were cultivated on half-strength Murashige-Skoog basal medium (Murashige and Skoog 1962), supplemented with $3.0 \%$ sucrose and $0.2 \%$ gellan gum at $25^{\circ} \mathrm{C}$ in continuous light condition.

\section{DNA extraction}

Total genomic DNA extraction followed Hoshi et al. (2010). The DNAs were extracted from fresh leaves from in vitro cultured plants. The individuals were ground into powder with liquid nitrogen and homogenized in the buffer containing $1 \mathrm{M}$ Tris- $\mathrm{HCl}(\mathrm{pH} 8.0), 20 \mathrm{mM}$ EDTA, $1.4 \mathrm{M}$ $\mathrm{NaCl}, 2 \%$ cetyltrimethylammonium bromide and $0.5 \%$ mercaptoethanol. The homogenate was extracted three times with an equal volume of chloroform-isoamyl alcohol (24:1) for $10 \mathrm{~min}$. The DNA was precipitated with isopropyl alcohol at $-20^{\circ} \mathrm{C}$ for $30 \mathrm{~min}$. The DNA pellet was washed with $70 \%$ ethanol, dried, and dissolved in $200 \mu \mathrm{L}$ TE overnight. On the second day, $1 \mu \mathrm{L}$ of $1 \mathrm{mg} \mathrm{mL}^{-1}$ RNase was added, and the solution was incubated at $37^{\circ} \mathrm{C}$ for $1 \mathrm{~h}$ in a water bath. The DNA was treated as in the procedures of the first day and finally dissolved in $50 \mu \mathrm{L} \mathrm{TE}$.

\section{RAPD amplification}

We followed the instruction of 10 mer kit (Operon technologies, Alameda, CA, U.S.A.) to amplify the DNA samples with a number of 1200 primers. PCR was performed in a volume of $20 \mu \mathrm{L}$. The reaction mixture contained $0.1 \mu \mathrm{L}$ Taq DNA Polymerase (TOYOBO CodeNo.TAP-211), $2 \mu \mathrm{L}$ dNTPs ( $2 \mathrm{mM}$ each), $2 \mu \mathrm{L} 10 \times$ Taq-buffer, $13.9 \mu \mathrm{L}$ MillQ water, $1 \mu \mathrm{L}$ primer $(10 \mathrm{pmol}$ of each primer), and $1 \mu \mathrm{L}$ template DNA (1 ng). The DNA amplification was performed on a PCR thermalcycler (Program Temp Control System PC-708, Astec). The standard amplification condition was $94^{\circ} \mathrm{C}$ for $5 \mathrm{~min}$ followed by 45 cycles of $94^{\circ} \mathrm{C}$ for $0.5 \mathrm{~min}, 42^{\circ} \mathrm{C}$ for $0.5 \mathrm{~min}, 72^{\circ} \mathrm{C}$ for $1 \mathrm{~min}$, and the reaction was completed by a final extension step of $72^{\circ} \mathrm{C}$ for $10 \mathrm{~min}$. Amplified PCR products were performed onto $1.0 \%$ agarose gel electrophoresis in $1 \times \mathrm{TAE}$ buffer at $100 \mathrm{~V}$ for $40 \mathrm{~min}$. The DNA bands were visualized using a UV transilluminator (Funakoshi, NTM-20) after staining with $0.5 \mu \mathrm{g} \mathrm{mL} \mathrm{m}^{-1}$ ethidium bromide for $15 \mathrm{~min}$.

Table 1. Source of the materials of three species of Drosera spatulata complex and its related species.

\begin{tabular}{|c|c|c|c|c|c|}
\hline Species & $\begin{array}{l}\text { Accession } \\
\text { number }\end{array}$ & $\begin{array}{l}\text { Chromosome } \\
\text { number }(2 n)\end{array}$ & $\begin{array}{l}\text { Karyotype } \\
\text { formula }^{b}\end{array}$ & Ploidy level & $\begin{array}{l}\text { Used plants for } \\
\text { DNA extraction }\end{array}$ \\
\hline D. rotundifolia & 010816 Sera-1 & 20 & $20 \mathrm{M}$ & Diploid & in vitro culture \\
\hline D. spatulata & Jpn Ha4x-6 & 40 & $40 \mathrm{~S}$ & Tetraploid & in vitro culture \\
\hline D. tokaiensis & Jpn Ha6x-9 & 60 & $20 \mathrm{M}+40 \mathrm{~S}$ & Hexaploid & in vitro culture \\
\hline
\end{tabular}

${ }^{a}$ Plant sources of three Japanese species are described in Hoshi and Kondo (1998). ${ }^{b}$ M: middle size chromosome, S: small size chromosome (see Hoshi and Kondo 1998). 


\section{Results and discussion}

A total of 1200 decamer random sequences were initially screened to select the analysis primers to be used. For the purpose of clearing up the ambiguous bands in three Drosera species and it closed species bands, all species were used and primers that did not generate bands in the fingerprints were not retained.

A total of 534 primers selected from OPA-01 through OPBH-20 primers were tested in each of the three Drosera species accessions for examining the RAPD pattern. The typical results of RAPD fingerprinting in the three species are shown in Fig. 3. Using all primers from OPA to OPBH series, the RAPD generated many bands in the range of 100-3000 bp in D. rotundifloria,
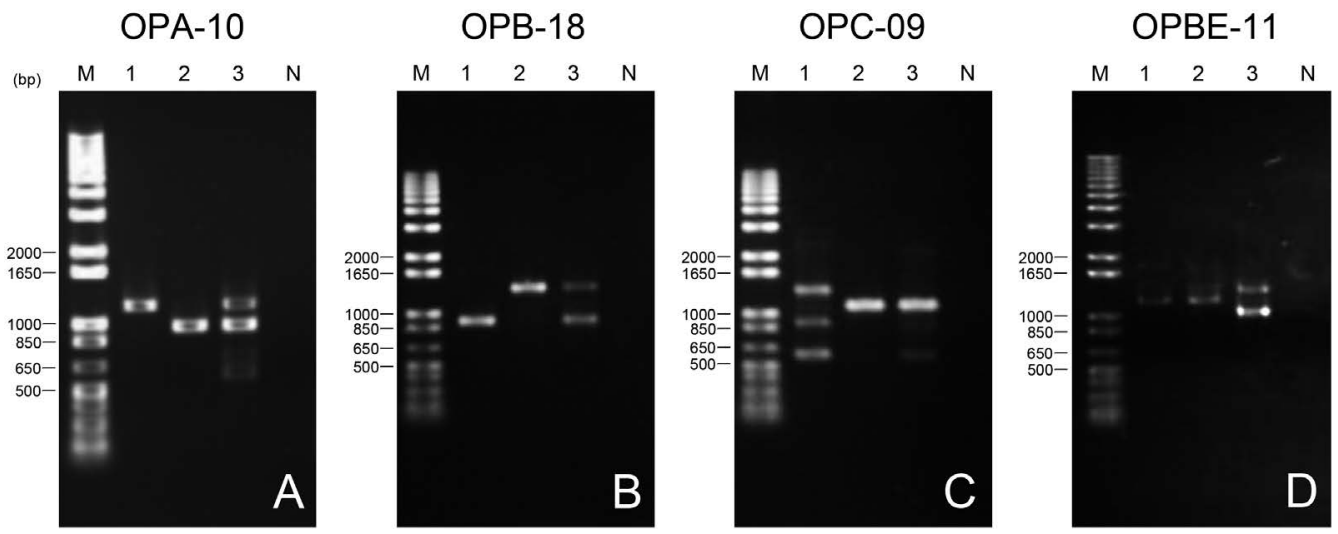

Fig. 3. Electrophoresis patterns of DNA amplification products obtained by RAPD primers of OPA-10 (A), OPB-18 (B), OPC-09 (C) and OPBE-11 (D) with template DNAs of D. rotundifolia (1), D. spatulata (2) and D. tokaiensis (3), without any template DNA (N). 1 kb Plus DNA Ladder was used for molecular marker (M).

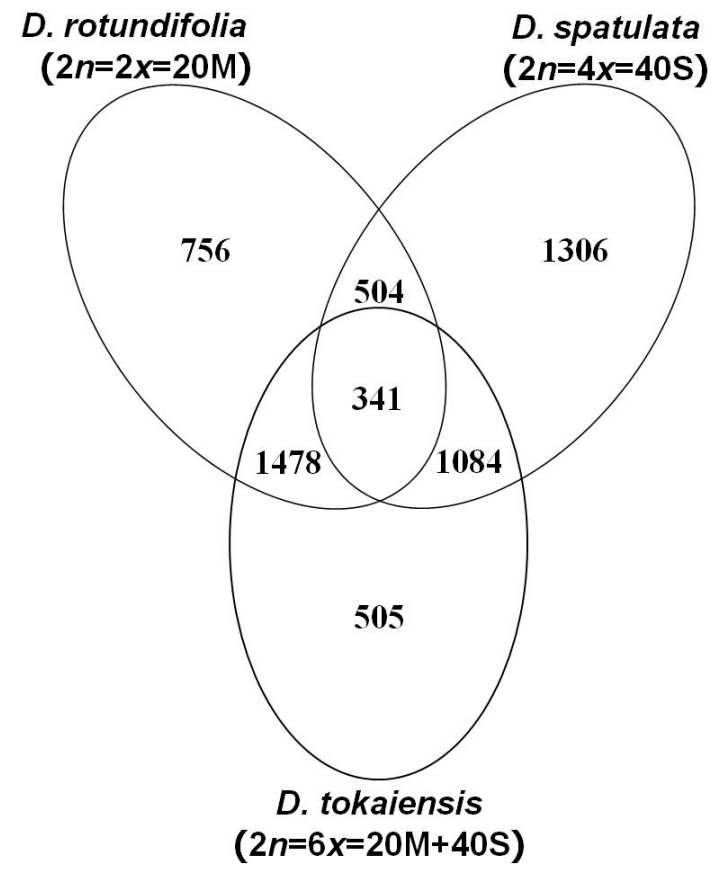

Fig. 4. Diagram of RAPD profiling between the three Drosera species. 
200-3000 bp in D. spatulata, and 100-3000 bp in D. tokaiensis. The maximum number of major amplicons generated by RAPD was 16, obtained with primer OPZ-11.

Primer series of OPD, OPI, OPJ, OPS, OPY, OPZ and OPAR revealed the presence of more than three bands shared by all Drosera species. In whole RAPD bands, 341 bands were common among all three species. Moreover, many common bands between two species were obtained. Drosera rotundifolia and D. spatulata showed 504 common bands, while D. spatulata and D. tokaiensis showed 1084 bands. D. rotundifolia and D. tokaiensis showed 1478 common bands. As for the electrophoresis result of specific DNA amplification, 756 and 505 bands were specific in $D$. rotundifolia and $D$. tokaiensis, respectively. In contrast, the number of specific bands observed in D. spatulata. Drosera spatulata was 1306 , screened and selected from whole 1200 random primers (Fig. 4).

The result of RAPD analysis in the present study showed that D. rotundifolia and D. tokaiensis have a higher percentage of common bands among the three species. The highest percentage of similarity between $D$. rotundifolia and $D$. tokaiensis seems to show a close relationship among the three species. However, previous molecular and cytogenetic works clearly demonstrated that $D$. tokaiensis was an allopolyploid ( $2 n=6 x=60$, hexaploid) with hybrid origin between $D$. rotundifolia ( $2 n=2 x=20$, diploid) as the paternal ancestor and D. spatulata $(2 n=4 x=40$, tetraploid) as the maternal ancestor (Hoshi et al. 2008, Hoshi et al. 2010, Shirakawa et al. 2012).

The relationship of genome compositions among the three species suggested that RAPD fragments were preferentially amplified from 20 middle size chromosomes in D. rotundifolia and $D$. tokaiensis. In consequence, most DNA fragments by RAPD had a priority to amplify from the genome set with middle size chromosome than small size chromosome, which resulted in the present study showing common bands between $D$. rotundifolia and D. tokaiensis (Fig. 4).

In a recent study on the anti-allergic effect of a fraction of Drosera plants to HMC-cells, $D$. tokaiensis had a stronger anti-allergic effect than D. rotundifolia and D. spatulata (Fukushima et al. 2009). The RAPD study showed that $D$. tokaiensis had not only a huge number of bands common to the other two species, but also many specific bands, even though $D$. tokaiensis is of amphiploidal origin between D. rotundifolia and D. spatulata (Fig. 4). The DNA sequences amplified as RAPD bands specific to D. tokaiensis (Fig. 3D) might occur after speciation or chromosome differentiation.

Therefore, the chromosome information obtained from molecular studies, including the RAPD profiling, suggested that alloploidal genome formation during Drosera speciation might produce new advantageous characteristics for environmental adaptation.

\section{References}

Allan, H. H. 1961. Flora of New Zealand, Vol. 1. Government Printer, Wellington.

Bhau, B. S., Kalyani, M., Sarkar, T. and Siddhartha, P. S. 2009. PCR based molecular characterization of Nepenthes khasiana Hook. f. pitcher plant. Genet. Resour. Crop Evol. 56: 1183-1193.

Conran, J. G., Jaudzems, G. V. and Hallam, D. N. 1997. Droseraceae germination patterns and their taxonomic significance. Bot. J. Linn. Soc. 123: 211-223.

Fukushima, K., Nagai, K., Hoshia, Y., Masumoto, S., Mikami, I., Takahashi, Y., Oike, H. and Kobori, M. 2009. Drosera rotundifolia and Drosera tokaiensis suppress the activation of HMC-1 human mast cells. J. Ethnopharmacol. 125: 90-96.

Horikawa, Y. 1976. Atlas of the Japanese Flora II. Gakken, Tokyo (in Japanese).

Hoshi, Y. and Kondo, K. 1998. Chromosome differentiation in Drosera, Subgenus Rorella, Section Rossolis. Cytologia 63: 199-211.

Hoshi, Y., Shirakawa, J., Hasebe, M., Fukushima, K. and Kondo, K. 2008. Tandem repeat rDNA sequences derived from parents were stably maintained in hexaploids of Drosera spathulata complex (Droseraceae). Cytologia 73: 313-325.

Hoshi, Y., Shirakawa, J., Takeo, M. and Nagano, K. 2010. A molecular genetics of Drosera spatulata complex by using of 
RAPD analysis. Chromosome Bot. 5: 23-26.

Hoyo, Y. and Tsuyuzaki, S. 2013. Characteristics of leaf shapes among two parental Drosera species and a hybrid examined by canonical discriminant analysis and a hierarchical Bayesian model. Am. J. Bot. 100: 817-823.

Juniper, B. E., Robins, R. J. and Joel, D. M. 1989. The Carnivorous Plants. Academic Press, London.

Marchant, N. G. and George, A. S. 1982. Drosera. In: George, A. S. (ed.). Flora of Australia, Vol. 8. Australian Government Publishing Service, Canberra. pp. 9-64.

Merrill, E. D. 1923. An Enumeration of Philippine Flowering Plants, Vol. 2. Bureau of Printing, Manila.

Murashige, T. and Skoog, F. 1962. A revised medium for rapid growth and bioassays with tobacco tissue cultures. Physiol. Plant. 15: 473-497.

Nakano, M., Kinoshita, E. and Ueda, K. 2004. Life history traits and coexistence of an amphidiploid, Drosera tokaiensis, and its parental species, D. rotundifolia and D. spatulata (Droseraceae). Plant Species Biol. 19: 59-72.

Rivadavia, F., Kondo, K., Kato, M. and Hasebe, M. 2003. Phylogeny of the sundews, Drosera (Droseraceae) based on chloroplast $r b c L$ and nuclear 18S ribosomal DNA sequences. Am. J. Bot. 90: 123-130.

Seine, R. and Barthlott, W. 1994. Some proposals on the infrageneric classification of Drosera L. Taxon 43: 583-589.

Sharma, S. K., Dawson, I. K. and Waugh, R. 1995. Relationships among cultivated and wild lentils revealed by RAPD analysis. Theor. Appl. Genet. 91: 647-654.

Shirakawa, J., Nagano, K. and Hoshi, Y. 2012. Polyploid genome structure of Drosera spatulata complex (Droseraceae). Cytologia 77: 97-106.

Takahashi, H. and Sohma, K. 1982. Pollen morphology of the Droseraceae and its related taxa. Sci. Rep. Tohoku Univ. Ser. 4 38: 81-156.

van Steenis, C. G. G. V. 1953. Droseraceae. In: van Steenis, C. G. G. V. (ed.). Flora Malesiana, Series I, Vol. 4. NoordhoffKolff N. V., Jakarta. pp. 377-380.

Williams, S. E., Albert, A. V. and Chase, W. M. 1994. Relationships of Droseraceae: A cladistics analysis of $r b c L$ sequence and morphological data. Am. J. Bot. 81: 1027-1037. 